\title{
Real Time Flood Alert System (RTFAS) for Puerto Rico
}

\section{Overview}

The Real Time Flood Alert System is a web-based computer program, developed as a data integration tool, and designed to increase the ability of emergency managers to rapidly and accurately predict flooding conditions of streams in Puerto Rico (fig. 1). The system includes software and a relational database to determine the spatial and temporal distribution of rainfall, water levels in streams and reservoirs, and associated storms to determine hazardous and potential flood conditions. The computer program was developed as part of a cooperative agreement between the U.S. Geological Survey Caribbean Water Science Center and the Puerto Rico Emergency Management Agency, and integrates information collected and processed by these two agencies and the National Weather Service.

\section{Introduction}

Floods are the most destructive and costly of all natural disasters in the United States, in terms of loss of life, and damage and destruction of property and infrastructure. The average cost of restoring property and infrastructure, between 1903 and 2007, was estimated at $\$ 5.24$ billion annually. Damage to property and infrastructure was lowest in 1906, with only $\$ 34$ million in associated costs, and was highest in 2005, due to Hurricane Katrina, with $\$ 125$ billion (costs are normalized to 2007 dollars). The loss of life due to floods varies greatly between years, and has ranged from 0 to 554 casualties per year since the early 1900 s (National Oceanic and Atmospheric Administration, 2009). Death statistics do not include those caused by Hurricane Katrina during the months of August and September 2005. Most of the flood-related deaths are caused by flash flooding.

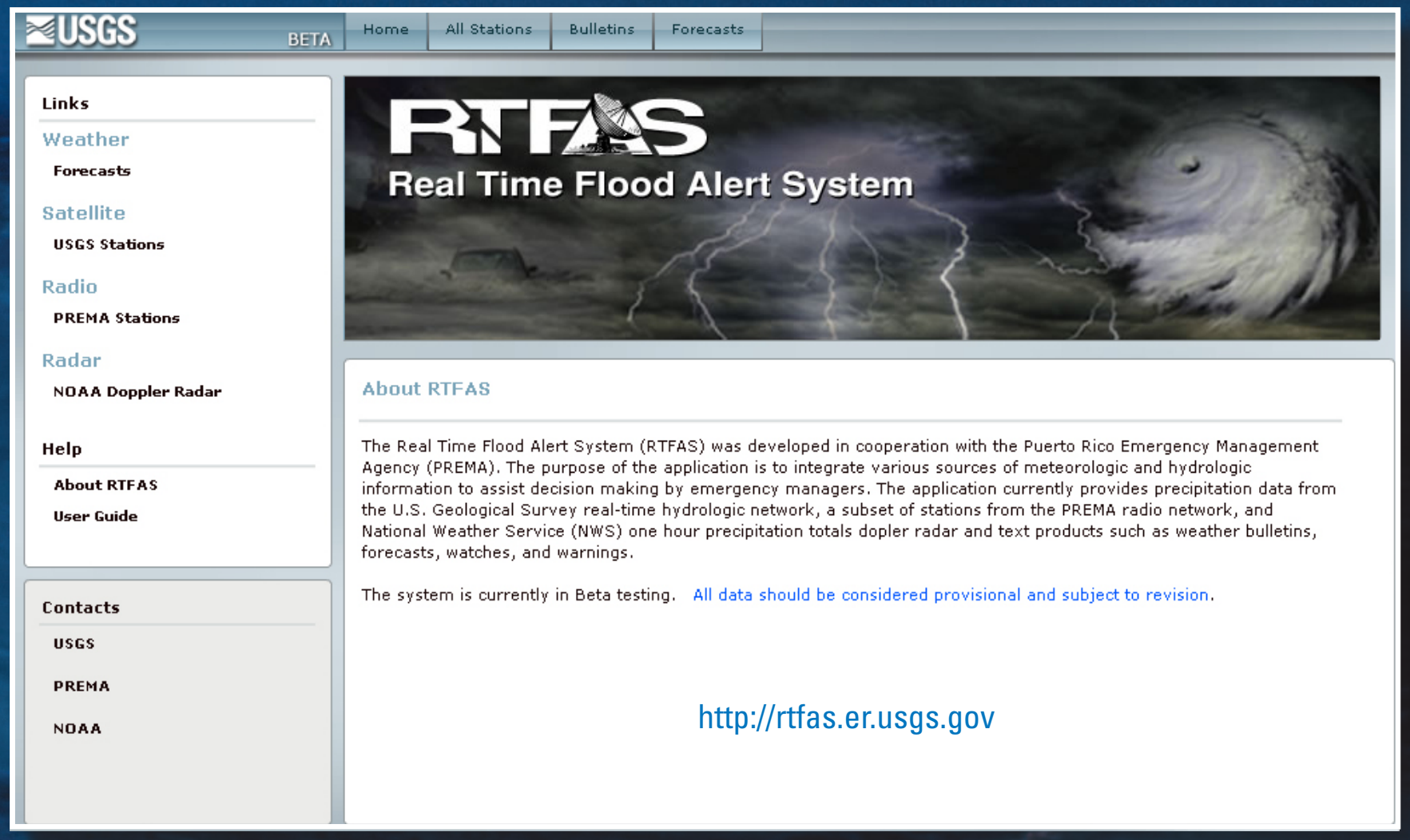

Figure 1. Real Time Flood Alert System Home page. 
In Puerto Rico, floods can be extremely destructive because of the island's steep, mountainous topography and relative proximity to dense population centers (fig 2). For example, in October 1985, the rainfall in Puerto Rico associated with a nearly stationary tropical depression caused 170 deaths, and damaged or destroyed about 3,000 homes (U.S. Geological Survey, 1989). Most of the island's major river systems have their headwaters in the central mountain range where rainfall during tropical storms and hurricanes is typically prolonged and intense. The stream valleys are narrow, relatively short in length, and steep-ideal conditions for the generation of flash flooding. Approximately, one-third of the population on the island lives in flood prone areas and the consequent potential for property damage and loss of life is very high.

In order to enhance the ability of emergency managers to rapidly and accurately anticipate floods, thereby increasing the lead-time available to handle the emergency, the U.S. Geological Survey Caribbean Water Science Center (USGS-CWSC) developed the Real-Time Flood Alert System (RTFAS) computer program. The objective of this program is to reduce the time needed to assess rainfall rates, the status of stage and discharge in rivers, and sudden changes to reservoir stage caused by an increase in upgradient streamflow.

RTFAS was developed as part of a cooperative agreement between the USGS and the Puerto Rico Emergency Management Agency (PREMA), and integrates information collected and processed by both agencies and the National Weather Service (NWS).

\section{Data Sources: Precipitation and Streamflow Networks, and Doppler Radar}

Although hydrologic networks may not be available for each geographic region in the United States, access to continuous or near real-time data from these networks is possible by contacting a local USGS Science Center. Available nearreal-time data used for early detection of extreme hydrologic events are:

1. Precipitation and meteorological stations

2. Streamflow gaging stations

3. Doppler radar

In Puerto Rico, some of the precipitation stations are operated by PREMA. This precipitation network is a cooperative flood warning system, called the Automated Local Evaluation in Real Time (ALERT). The ALERT system consists of nearly 50 automated rainfall stations transmitting

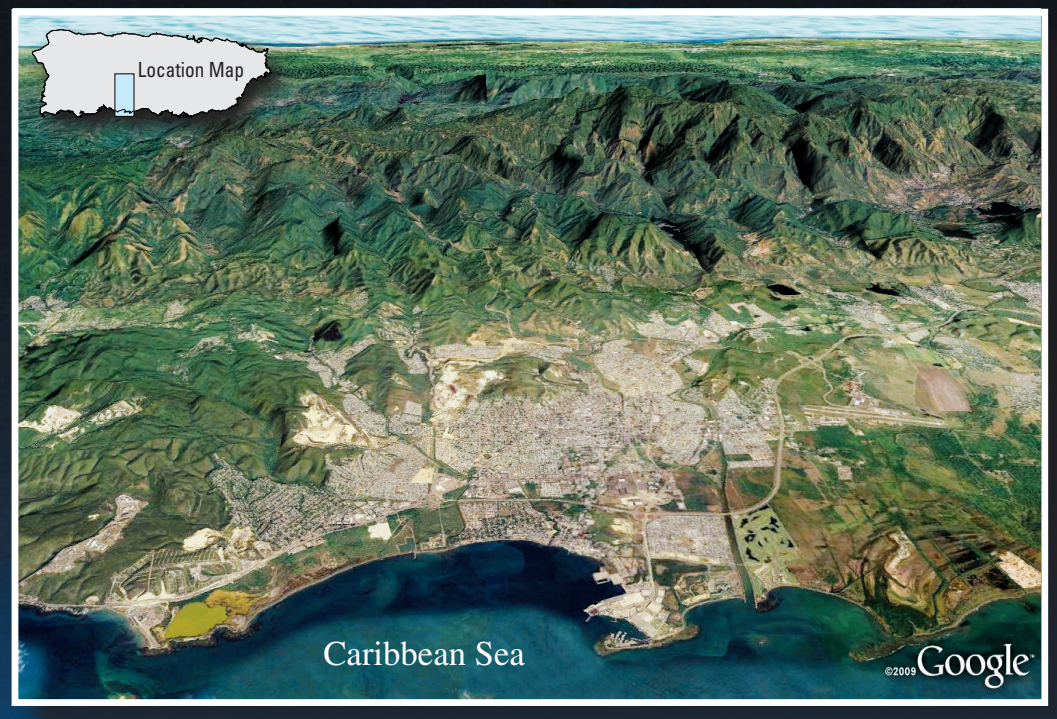

Image from @2010 Google, Data SIO, NOAA, U.S. Navy, NGA, GEBCO.

Image U.S. Geological Survey, (2010 Europa Technologies

Figure 2. Aerial view of the topography of Puerto Rico.

data at specific high frequencies. The rainfall stations' information is accessed by way of radio signal receiving equipment located at a base station. In addition, the USGS has a precipitation network that includes 132 rainfall stations that collect quasicontinuous data. The streamflow monitoring network is also operated and maintained by the USGS, and consists of approximately 190 automated stream gage-height and reservoir water-level stations. Gage height is converted to streamflow discharge using rating curves developed for each stream. The NWS Doppler radar is another source of information that complements the rainfall station, and gage height data obtained by the two hydrologic networks. The Doppler radar provides color coded images that display spatial information on instantaneous and cumulative rainfall throughout Puerto Rico, the United States, and the British Virgin Islands. The USGS stations are equipped with data collection platforms that transmit data, either on a self-timed or random reporting basis through the Geostationary Operational Environmental Satellite (GOES) to the USGS Caribbean Water Science Center. During normal operation, the stations transmit hourly data at 15-minute interval. During storm conditions, however, the station enters in an alert mode and begins transmitting data every 5 minutes if a sensor detects a sudden rise in the stream or reservoir stage-level, or a rapid rate of accumulation of precipitation.

Several agencies can provide access and interact during extreme events to facilitate data and information useful during hydrologic emergencies. This array allows the National Weather Service, River Forecast Center to use the USGS data to run flood prediction models. 


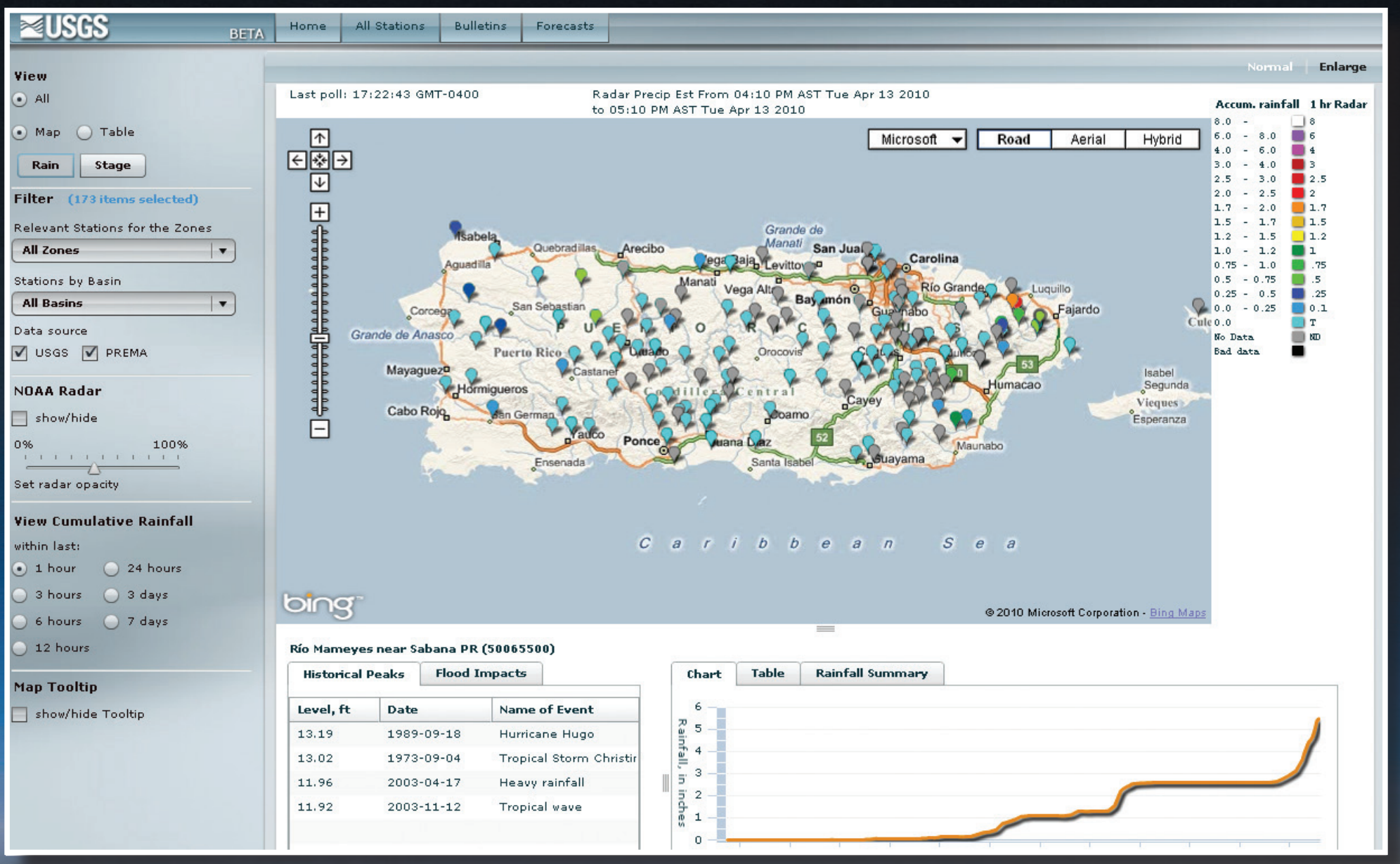

Figure 3. U.S. Geological Survey (USGS) and Puerto Rico Emergency Management Agency (PREMA) precipitation networks.

\section{RTFAS User Environment}

RTFAS was developed using Adobe Flex ${ }^{\mathrm{TM}}$, which generates web-based applications that are executed in the Adobe Flash Player; thus, the Adobe Flash Player plug-in is required. Adobe Flex ${ }^{\mathrm{TM}}$ generates Rich Internet Applications that allow real-time interactivity that is impossible to accomplish in standard Hypertext Markup Language (HTML) alone. The emergency managers can access RTFAS using any of the following browsers: Microsoft Internet Explorer®, Mozilla Firefox ${ }^{\circledR}$, Apple Safari ${ }^{\circledR}$, and Google Chrome ${ }^{\circledR}$.

\section{Interface Overview}

The RTFAS interface consists of four tabs: Home, All Stations, Bulletins, and Forecasts, through which the user can access information that is collected and processed by PREMA, USGS, and the NWS.

Once the interface is loaded, by accessing

http://rtfas.er.usgs.gov, the Home tab is displayed.

\section{Description of Interface Tabs}

\section{HOME - includes general information and shortcut} links.

ALL STATIONS - can display spatial information from the PREMA precipitation network, the USGS hydrologic network, and the NWS Doppler radar images.

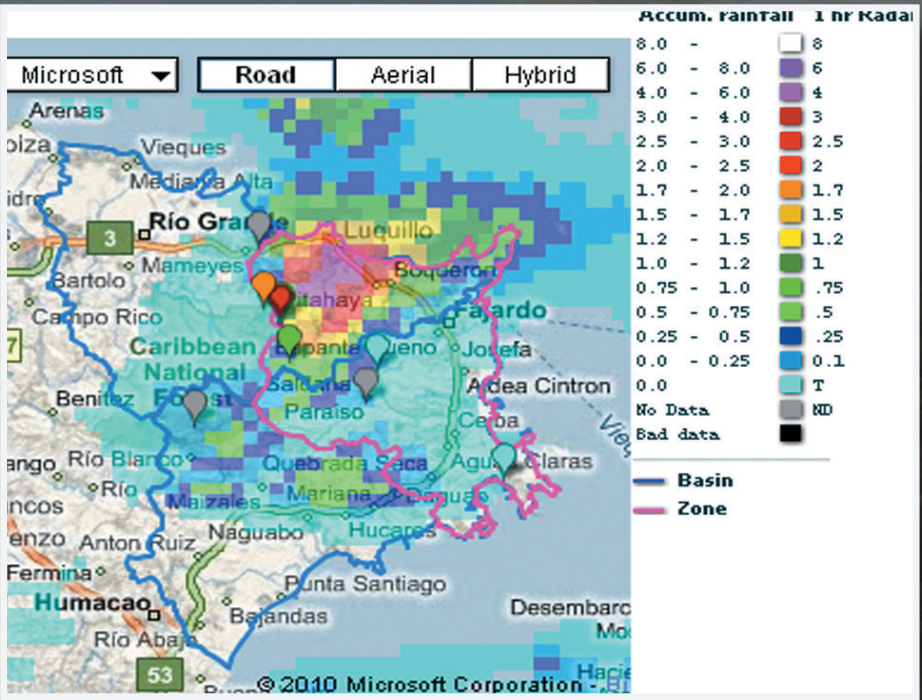

Figure 4. Example of monitored stations inside and outside the PREMA operational zone (Fajardo, zone \#11).

The display shows a map of Puerto Rico with the location of the PREMA and the USGS precipitation stations (fig. 3). Stations are graphed with an inverted drop symbol, which is also used to represent the amount of rainfall accumulation using a color coded legend listed at the right edge of the map. Rainfall accumulation varies when the selected time interval is changed. The RTFAS interface allows the user to select the time interval by choosing from the available options $(1,3,6,12,24$ hours, 3,7 days). The 1 -hour rainfall radar 


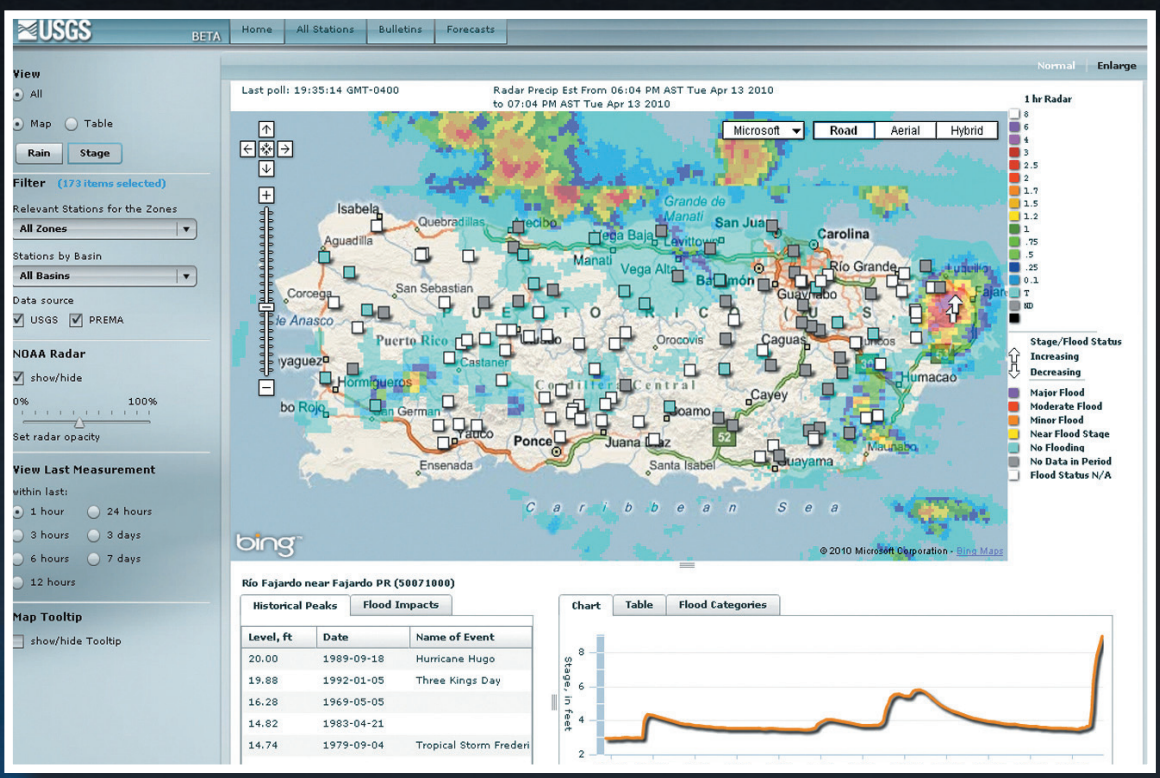

Figure 5. Gage-height (stage) at USGS surface-water stations and NWS Doppler radar image with $45 \%$ opacity.

image allows the user to prioritize the areas where rainfall intensity may be greatest.

When a station is selected with a click of the mouse, the program displays the chart and tabular data for individual sensor measurements during the last 24 hours, historical peak elevations, and if available, flood impact summaries caused by specific gage heights. This provides a quick overview of the data associated with each station. Station data, if selected, are automatically updated every 3 minutes in the charts and tables.
In Puerto Rico, PREMA is divided in 11 operational zones. Therefore, RTFAS allows each emergency manager to easily monitor their zone, allowing the list of stations to be filtered by zone. When a PREMA zone is selected, the zone and the hydrologic basins are delineated on the map and the stations within the hydrologic basins are displayed. Displaying all this information enhances the understanding of the relation between the measured parameters in the delineated hydrologic basin, even if the stations are located outside of the PREMA zone. It is important for the emergency manager to monitor all stations included within the boundaries of the hydrologic basin that contributes to the zone of operation assigned by PREMA (fig. 4).

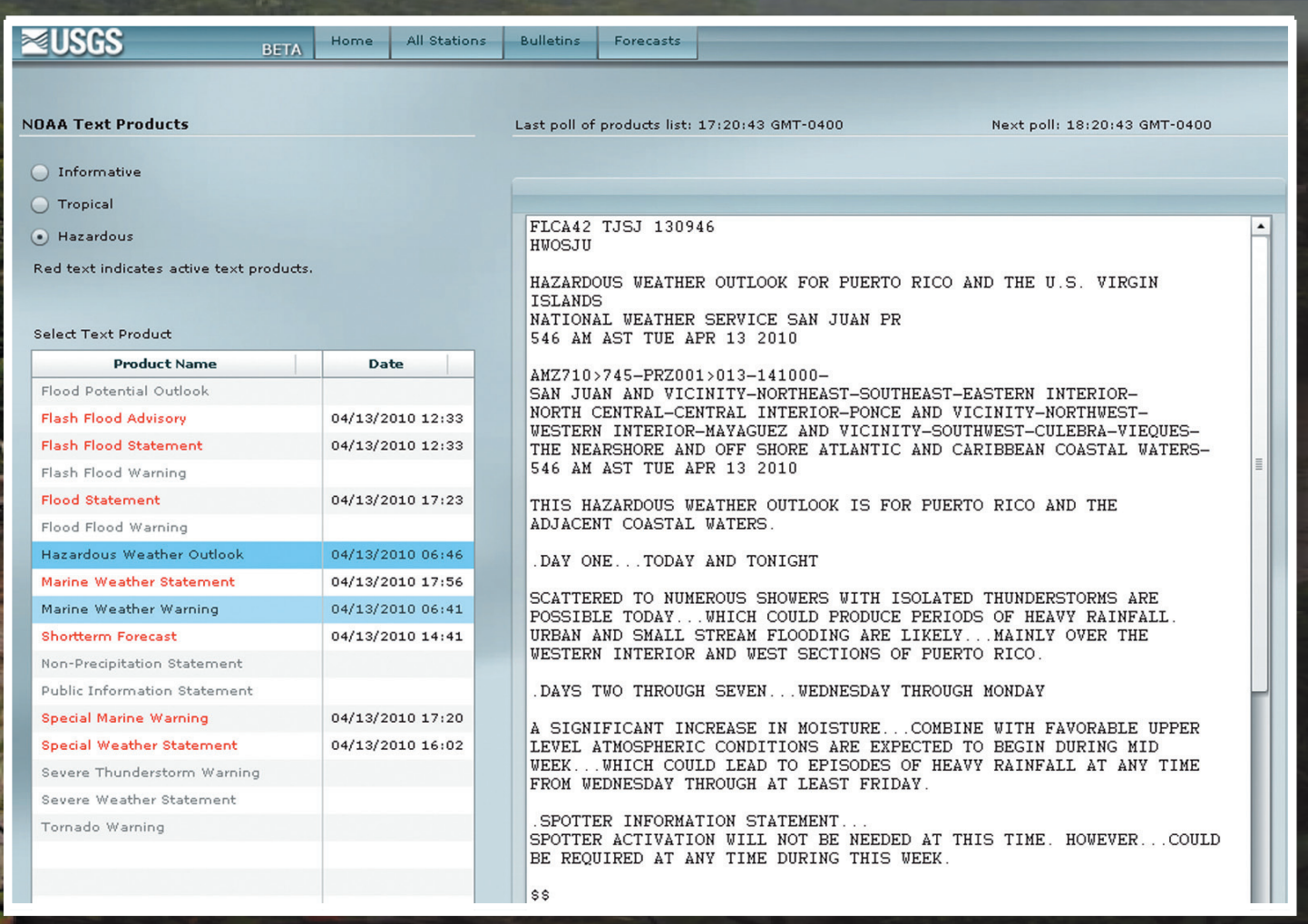

Figure 6. Active text products from the National Weather Service.
Streams are also displayed using a color-coded squared shape symbol (fig. 5) to determine the condition of the stream during an ongoing flooding event. Squares are colored ranging from "No Flooding" to "Major Flood" status, where a predetermined flood stage is indicative of the condition of the stream. Predetermined flood stage elevations are developed by NOAA to indicate flood status.

When the change in gage-height exceeds more than 6 inches for the preceding 15 minutes, the station's square icon will change to an up arrow ( $\uparrow)$, indicating that the level is increasing rapidly. A rapid decrease in gage-height is also important, and will be represented as a down arrow $(\downarrow)$. These arrows serve as a visual cue indicating the potential for stream stage peak or recession status.

In addition, stage and rainfall data can be viewed and toggled in both map and tabular formats. If a station is selected on one format, for example, by clicking on the Map marker corresponding to the station, RTFAS will synchronize the available information in the tabular format; therefore, the user will not have to scroll for the station on the table. 


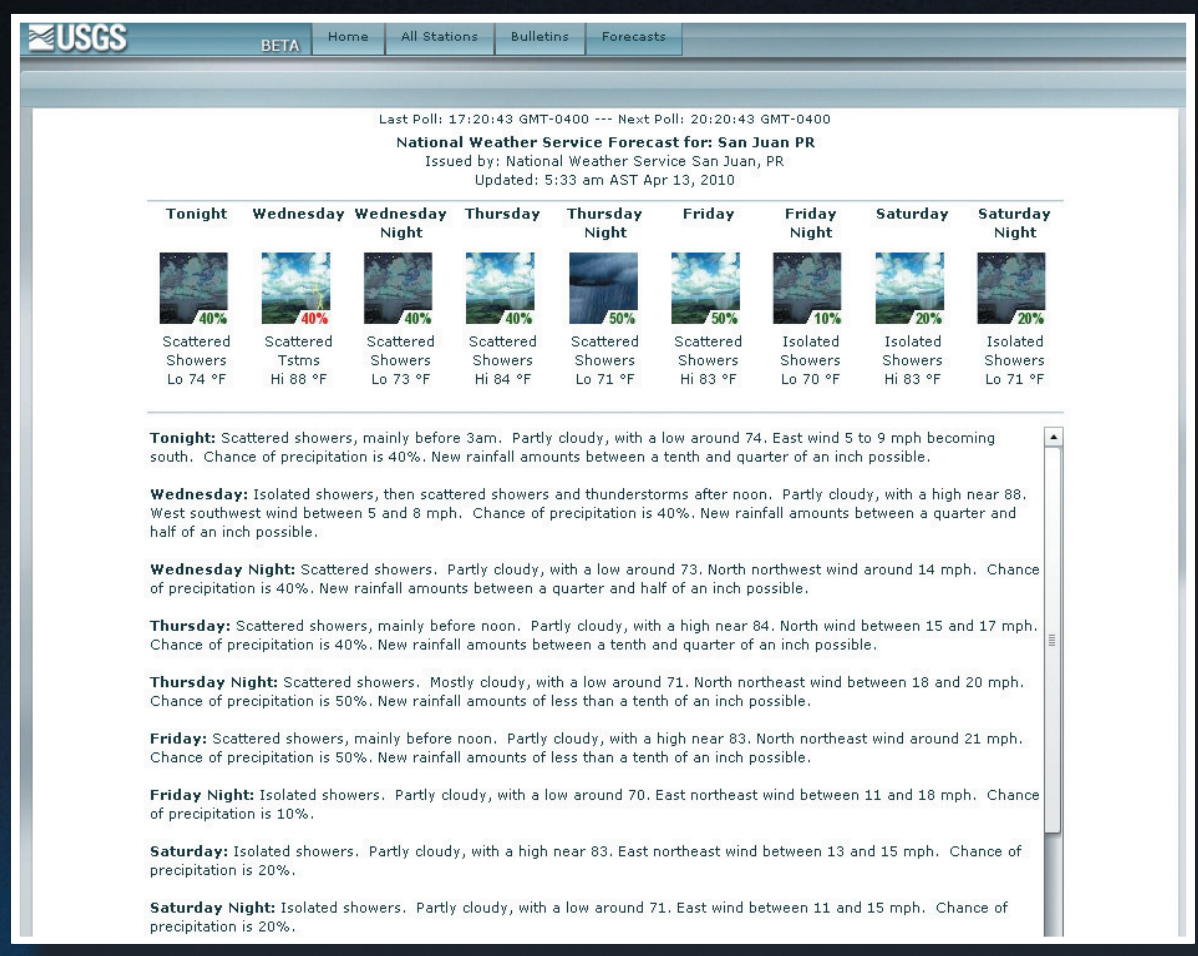

Figure 7. Real Time Flood Alert System (RTFAS), automatic compilation of 5-day (extended) weather summaries from the National Weather Service (NWS). information. It is important to indicate that RTFAS centralizes data compilations and facilitates access and information to and by users. Some of the information relevant during storms and extreme hydrologic events include: near real time streamflow discharge, rainfall accumulations, Doppler radar images, and the NOAA area forecast discussions.

Among the different sources of information used by RTFAS are: (1) Puerto Rico Emergency Management Agency VHF (very high frequency) radio stations - coded with the orange arrow, (2) USGS field data stationscoded with the green arrows, and (3) National Oceanic and Atmospheric Administration Doppler radar images and text products—coded with the blue arrows.

\section{PREMAs VHF transmissions include} information from the PREMA stations to the RTFAS server. The field stations transmit a VHF signal that is sent to the USGS National Water Information System (NWIS) server, which in turn is forwarded to RTFAS server.
BULLETINS - includes NWS text products: warnings, watches, area forecasts, and other related information (fig. 6). Products are grouped into three categories: informative, tropical and hazardous. The Bulletins tab also displays the products that remain active, shown in red. This feature eliminates products that are no longer active, thereby increasing the lead time available to examine imminent floods. The text product list is updated automatically by RTFAS every hour.

FORECASTS - consists of area forecast reports or weather summaries from the NWS (fig. 7). This tab provides a general indication of the weather conditions in Puerto Rico, and can provide information on future weather conditions. RTFAS updates the forecast information automatically every 3 hours.

\section{Data Flow}

The flow of data consists of three redundant data transmission systems (fig. 8). Although some of the information is generated onsite, data transmission is conducted and rerouted using three different transmission mediums: radio signals, the Internet, and satellite. Other relevant information, such as Doppler radar images and forecast products, are also used. This multi-system configuration ensures that timely information is available to be accessed by RTFAS, and in most cases, in near real-time without missing values or service interruptions.

The flowchart shown in figure 8 can be easily followed by looking at the different arrow colors. Each colororange, green, and blue-represents a different source of
The USGS streamflow monitoring network transmits gage-height data from streams throughout Puerto Rico. Gage-height data are converted into streamflow discharge using rating curves developed for each stream, and are made available to RTFAS through the NWIS database. In addition, RTFAS has access to rainfall stations maintained and operated by the USGS.

Finally, the NWS provides text products including area forecast discussions, and bulletins that are also incorporated into RTFAS. These can be downloaded from the NWS web servers, but are also available through the Emergency Managers Weather Information Network (EMWIN).

In addition to the text products, the NWS Doppler radar data are made available through the NWS web servers. RTFAS downloads the accumulated 1-hour rainfall Doppler radar data at 15 -minute intervals.

\section{Summary}

RTFAS is a web-based computer interface developed as a data integration tool, and designed to increase the ability of emergency managers to rapidly and accurately predict flooding conditions of streams. The hydrologic and meteorological data are provided by PREMA, USGS, and the NWS. The interface consists of several tabs through which the user can quickly access information collected and processed by the aforementioned agencies. RTFAS was developed using Adobe Flex ${ }^{\mathrm{TM}}$, which generates web-based applications that execute in Adobe Flash Player, making it widely available on many computer platforms and web browsers. 


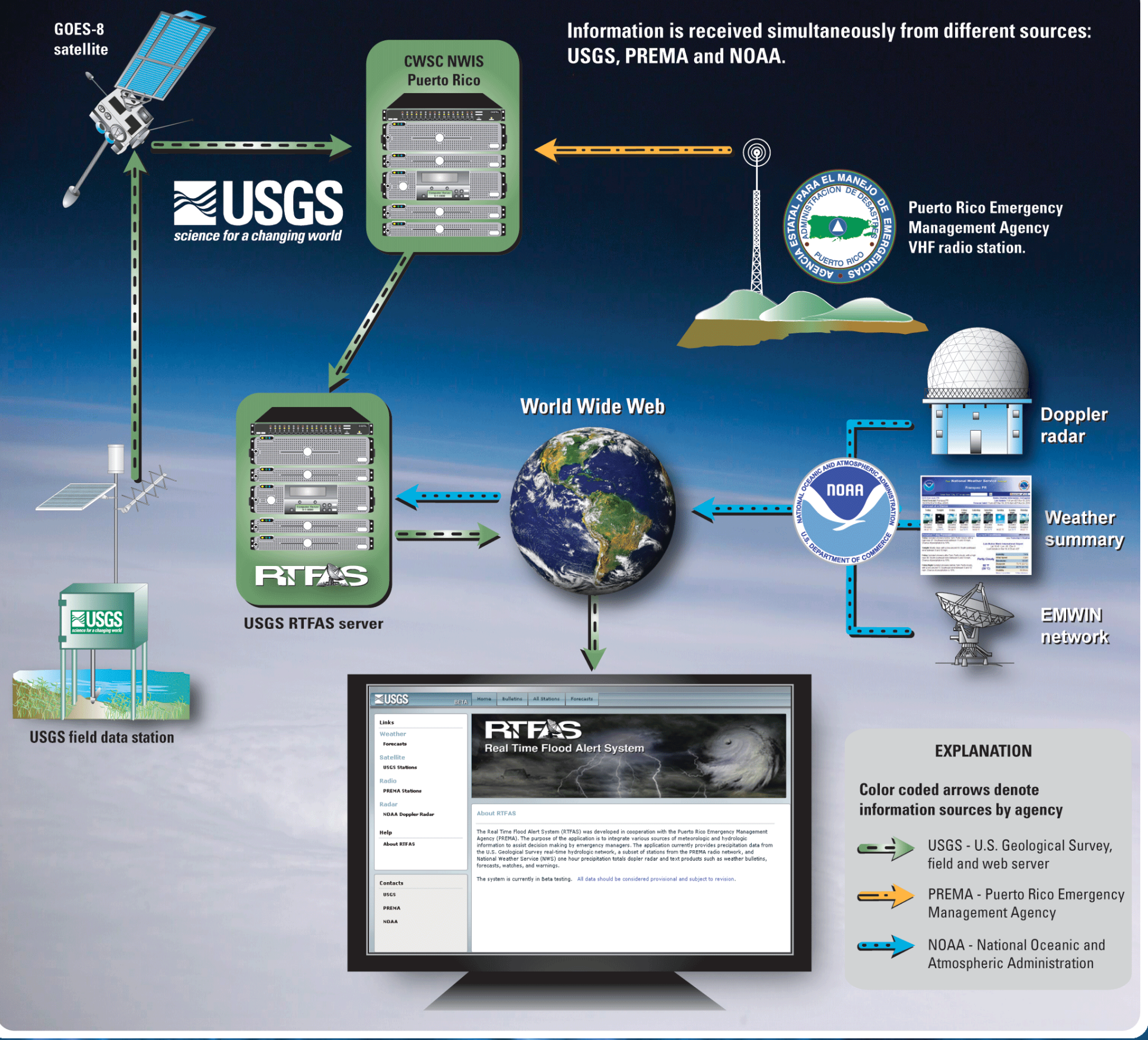

Figure 8. Real Time Flood Alert System (RTFAS) data flow chart.

\section{References Cited}

Hydrologic Information Center National Weather Service, March 19, 2009, Flood Losses: Compilation of Flood Loss Statistics, National Weather Service, accessed April 5, 2010, at http:// www.nws.noaa.gov/oh/hic/flood_stats/Flood_loss_time_series. shtml.

U.S. Geological Survey, 1989, Puerto Rico Floods and Droughts, National Water Summary 1988-89, United States Geological Survey Water Supply Paper 2375, p. 475.
Question related to this software can be directed to the author:

The information is available in the publication

"Real Time Flood Alert System (RTFAS) for Puerto Rico" at http://pubs.usgs.gov/of/2010/3029/

Dianne López-Trujillo

U.S. Geological Survey

GSA Center, bldg 651 Federal Drive, Suite 400-15

Guaynabo, P.R. 00965-5703

(787) $749-4346$ ext. 257

dlopez@usgs.gov

U.S. Department of the Interior KEN SALAZAR, SECRETARY
U.S. Geological Survey Marcia McNutt, Director 